\title{
Blood Lactate and Acid-Base Balance of World-Class Amateur Boxers After Three 3-Minute Rounds in InTERnational Competition
}

\author{
Christine Hanon, ${ }^{1}$ Jean Savarino, ${ }^{2}$ and Claire Thomas ${ }^{1,3}$ \\ ${ }^{1}$ Laboratory of Sport, Expertise and Performance, French National Institute of Sports (INSEP), Paris, France; ${ }^{2}$ French Boxing \\ Federation, Paris, France; and ${ }^{3}$ STAPS Department, University of Evry Val d'Essonne, Evry, France
}

\begin{abstract}
Hanon, C, Savarino, J, and Thomas, C. Blood lactate and acid-base balance of world-class amateur boxers after three 3-minute rounds in international competition. J Strength Cond Res 29(4): 942-946, 2015-To examine the blood metabolic responses of world-class boxers involved in international competition (Test match), 33 male boxers (mean \pm $S D$ ) competing internationally across all the official weight categories were studied on 2 different occasions: Test match 1 (team A against team B) and Test match 2 (team $A$ against team $C$ ). Blood samples were collected after the third round for both Test matches for all teams except team B. For all Test matches and boxers, mean blood lactate concentration ([BLac]), bicarbonate concentration, hemoglobin $\mathrm{O}_{2}$ saturation $\left(\mathrm{SaO}_{2}\right)$, partial pressure for $\mathrm{CO}_{2}$ $\left(\mathrm{PCO}_{2}\right)$, and $\mathrm{pH}$ were $13.6 \pm 2.4 \mathrm{mmol} \cdot \mathrm{L}^{-1}, 13.2 \pm 2.3$ $\mathrm{mmol} \cdot \mathrm{L}^{-1}, 95.0 \pm 2.6 \%, 32.0 \pm 5.5 \mathrm{~mm} \mathrm{Hg}$, and $7.22 \pm$ 0.06 with $7 / 20$ final $\mathrm{pH}$ values $<7.20$. The intermediate category $(60-64 \mathrm{~kg})$ was characterized by the greatest [BLac] $(14.8 \pm 2.9)$ compared with the heaviest and lighter boxers $\left(\sim 12 \mathrm{mmol} \cdot \mathrm{L}^{-1}\right)$. During the second match (team $A$ again team $\mathrm{C}$ ), a significant difference between $\mathrm{pH}, \mathrm{PCO}_{2}$, and $\mathrm{SaO}_{2}$ values was observed with no concomitant difference in [BLac] suggesting a better buffering capacity in team A. This result highlights the need for a welldeveloped anaerobic and buffering capacity and indicates that world-class boxers must be able to tolerate a substantial level of acidosis to produce high levels of boxing activity until the end of a match.
\end{abstract}

KEY WoRDS boxing, elite boxers, blood metabolic responses, international competition

Address correspondence to Christine Hanon, christine.hanon@insep.fr. 29(4)/942-946

Journal of Strength and Conditioning Research

(c) 2015 National Strength and Conditioning Association

942

Journal of Strength and Conditioning Research

\section{INTRODUCTION}

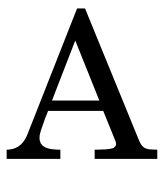
mateur boxing is characterized by intermittent movement patterns with varying energetic demands. In the past decades, the duration and number of rounds have varied from between three to five 2-minute rounds and three 3-minute rounds. At the 2012 London Olympic Games, men's bouts took place over 3 rounds of 3 minutes each with 1-minute intervals in between. Each country is limited to 1 athlete in each category, thus making qualifying for and achieving success at the Olympic Games extremely difficult. Therefore, from a practical point of view, valid competition data may aid in designing proper conditioning programs for elite boxers and to optimize physical conditioning. Boxing conditions cannot be easily simulated in controlled laboratory settings or in simulated bouts that do not induce the same involvement from boxers. Therefore, boxing-bout data need to be acquired during actual competition. The results could then be used to regulate training protocols for the characteristic demands of the three 5-minute rounds of amateur boxing.

Boxing has been defined as a technical sport generating high levels of energetic expenditure (7). Because of the difficulty in measuring oxygen uptake during an actual or simulated boxing competition, there are currently no data available regarding aerobic contribution. The aerobic challenge of competition has been demonstrated by heart rate values (HR) recorded during simulated bouts or by maximal oxygen consumption $\left(\dot{\mathrm{V}}_{2} \mathrm{max}\right)$ values of the boxing population, measured during an incremental running test. During simulated fights, our team has previously reported final heart rate, compared with the incremental test maximal heart rate, to be maximal at the end of the third round $\left(185 \pm 3 \mathrm{~b} \cdot \min ^{-1}\right)(18)$, confirming work by Ghosh et al. (13) $\left(178 \mathrm{~b} \cdot \mathrm{min}^{-1}\right)$ or Smith (17), respectively, in an Indian or English equivalent population. It is known that HR may be influenced by other crucial factors in boxing competition, such as psychological stress and mental concentration (4), as well as fluid loss (15), and may lead to an inaccurate estimation of metabolic demands. Therefore, the conclusions reported from these data could be questionable. A relative $\dot{\mathrm{V}}_{2} \max$ value between 58 and 
TABLE 1. Blood metabolic data (mean $\pm S D$ ) recorded during the 2 Test matches. ${ }^{*} \dagger$

\begin{tabular}{|c|c|c|c|c|c|c|c|c|}
\hline Categories (kg) & 48 & & 51 & & 54 & 57 & 60 & 64 \\
\hline Subjects & 3 & & 2 & & 3 & 3 & 3 & 3 \\
\hline $\mathrm{pH}(\mathrm{a} . \mathrm{u})$ & $7.29 \pm 0.05$ & 7.23 & \pm 0.11 & 7.23 & $3 \pm 0.04$ & $7.19 \pm 0.08$ & $7.20 \pm 0.04$ & $7.20 \pm 0.04$ \\
\hline$\left[\mathrm{HCO}_{3}{ }^{-}\right]\left(\mathrm{mmol} \cdot \mathrm{L}^{-1}\right)$ & $14.0 \pm 1.3$ & 12.8 & \pm 2.5 & 12.1 & \pm 0.6 & $13.2 \pm 2.8$ & $14.9 \pm 5.4$ & $12.7 \pm 1.9$ \\
\hline $\mathrm{SaO}_{2}(\%)$ & $97.0 \pm 2.0$ & 95.5 & \pm 4.9 & 94.7 & \pm 4.0 & $96.0 \pm 1.0$ & $93.6 \pm 5.1$ & $93.6 \pm 0.6$ \\
\hline $\mathrm{PCO}_{2}(\mathrm{~mm} \mathrm{Hg})$ & $29.2 \pm 4.3$ & 31.3 & \pm 4.9 & 28.8 & $3 \pm 3.7$ & $35.3 \pm 4.9$ & $32.6 \pm 6.8$ & $32.1 \pm 3.1$ \\
\hline$[\mathrm{BLac}] \mathrm{mmol} \cdot \mathrm{L}^{-1}$ & $11.4 \pm 1.5$ & 12.9 & \pm 0.4 & 13.2 & \pm 0.8 & $15.4 \pm 2.6$ & $13.3 \pm 1.3$ & $17.0 \pm 2.3$ \\
\hline Categories $(\mathrm{kg})$ & \multicolumn{2}{|l|}{69} & \multicolumn{2}{|c|}{75} & \multicolumn{2}{|r|}{81} & 91 & Mean $\pm S D$ \\
\hline Subjects & \multicolumn{2}{|l|}{3} & \multicolumn{2}{|c|}{3} & \multicolumn{2}{|c|}{2} & 4 & 33 \\
\hline $\mathrm{pH}(\mathrm{a} . \mathrm{u})$ & \multicolumn{2}{|l|}{$7.22 \pm 0.08$} & \multicolumn{2}{|c|}{$7.19 \pm 0.08$} & \multicolumn{2}{|c|}{$7.21 \pm 0.04$} & $7.26 \pm 0.03$ & $7.22 \pm 0.06$ \\
\hline$\left[\mathrm{HCO}_{3}{ }^{-}\right]\left(\mathrm{mmol} \cdot \mathrm{L}^{-1}\right)$ & \multirow{2}{*}{\multicolumn{2}{|c|}{$\begin{array}{l}12.6 \pm 2.0 \\
96.0 \pm 2.6\end{array}$}} & \multicolumn{2}{|c|}{$12.0 \pm 1.9$} & \multicolumn{2}{|c|}{$12.0 \pm 0.4$} & $14.0 \pm 2.6$ & $13.2 \pm 2.3$ \\
\hline $\mathrm{SaO}_{2}(\%)$ & & & \multicolumn{2}{|c|}{$96.3 \pm 2.5$} & \multicolumn{2}{|c|}{$92.0 \pm 0.9$} & $95.0 \pm 1.0$ & $95.0 \pm 2.6$ \\
\hline $\mathrm{PCO}_{2}(\mathrm{~mm} \mathrm{Hg})$ & \multicolumn{2}{|l|}{$34.3 \pm 6.2$} & \multicolumn{2}{|c|}{$30.4 \pm 2.2$} & \multicolumn{2}{|c|}{$32.6 \pm 5.6$} & $33.2 \pm 3.7$ & $32.0 \pm 5.5$ \\
\hline$[\mathrm{BLac}] \mathrm{mmol} \cdot \mathrm{L}^{-1}$ & \multicolumn{2}{|l|}{$13.8 \pm 2.1$} & \multicolumn{2}{|c|}{$14.2 \pm 2.7$} & \multicolumn{2}{|c|}{$14.4 \pm 0.8$} & $11.6 \pm 2.9$ & $13.6 \pm 2.4$ \\
\hline
\end{tabular}

$*\left[\mathrm{HCO}_{3}{ }^{-}\right]=$bicarbonate concentration; $\mathrm{SaO}_{2}=$ hemoglobin $\mathrm{O}_{2}$ saturation; $\mathrm{PCO}_{2}=$ partial pressure for $\mathrm{CO}_{2} ;[\mathrm{BLac}]=$ blood lactate concentration.

$\dagger$ Subjects of team $\mathrm{A}$ (Test match 1 ) and teams $\mathrm{A}^{\prime}$ and $\mathrm{C}$ included (Test match 2), $n=33$.

$64 \mathrm{ml} \cdot \mathrm{min}^{-1} \cdot \mathrm{kg}^{-1}$ has been reported for groups of senior international boxers $(12,14,17)$, with a value of 69.1 $\mathrm{ml} \cdot \mathrm{min}^{-1} \cdot \mathrm{kg}^{-1}$ for a British Olympic medalist (17), suggesting the requirement for an amateur boxer to have a well-developed aerobic capacity. It seems that determining an accurate aerobic contribution in actual boxing conditions is difficult; however, the importance of having a high aerobic capacity has been demonstrated in boxingspecific literature (17).

In comparison, anaerobic contribution can be measured by postexercise blood lactate response and is more broadly documented. Numerous studies performed with well-trained boxers observed a postcompetition blood lactate concentration ([BLac]) equivalent to $8 \mathrm{mmol} \cdot \mathrm{L}^{-1}(13,18)$ and 12 $\mathrm{mmol} \cdot \mathrm{L}^{-1}(8)$ in trained and novice boxers, respectively. Based on a very large cohort of international junior and senior boxers $(n>150)$, the range of values presented by Smith (17) with different contest formats, was 6 and $18 \mathrm{mmol} \cdot \mathrm{L}^{-1}(17)$. This final [BLac] does not systematically reflect the [BLac] during the round since the boxing intensity fluctuates widely throughout a round. Therefore, the movement pattern (throwing punches for example) occurring during the last 30 seconds could largely induce the [BLac] measured at the end of the round. Furthermore, according to the level of the buffering capacity of the boxer, a similar [BLac] could induce different levels of acidosis (11).

Therefore, the aim of this study was to describe blood metabolic responses such as [Blac], $\mathrm{pH}$, blood bicarbonate concentration $\left(\left[\mathrm{HCO}_{3}{ }^{-}\right]\right)$, hemoglobin $\mathrm{O}_{2}$ saturation $\left(\mathrm{SaO}_{2}\right)$, and partial pressure for $\mathrm{CO}_{2}\left(\mathrm{PCO}_{2}\right)$ of worldclass boxers during international competition (official Test matches) performed with official rules (three 3-minute bouts).

\section{Methods}

\section{Experimental Approach to the Problem}

Data were collected at 2 different official competitions (Test matches 1 and 2), from 3 national teams representing 3 countries $(\mathrm{A}, \mathrm{B}$, and $\mathrm{C})$ that had selected their best national boxers in each category. All the boxers tested in this study trained twice a day.

Test match 1 was organized in January between 2 European countries (A and $\mathrm{B}$ ), that corresponded to the preparation period. Test match 2 was organized in May with a European country (team A) opposite to an Americas team (team C) that corresponded to a precompetitive period. Regarding team 1, the different categories were always represented by the same boxers in both Test matches, which explain why we called it $\mathrm{A}^{\prime}$ during the second Test match. The matches were official Test matches with public and official referees and were not organized specifically for the study. Data were only collected for team A, $\mathrm{A}^{\prime}$, and C. Over 7 days preceding Test match 2, the training load was similar for team $\mathrm{A}^{\prime}$ and $\mathrm{C}$ (mutual training camp). During these Test matches, team A won against team $\mathrm{B}$ and team $\mathrm{A}^{\prime}$ against team $\mathrm{C}$.

\section{Subjects}

Twenty-eight boxers (mean $\pm S D$ ) age: $21.5 \pm 2.1$ (range from 19 to 25 years) years, body mass: $67.0 \pm 14.6 \mathrm{~kg}$, selected for their respective national team, 6 had already won a world medal (Olympic Games or World Championships), took part in this study. Informed consent documents were signed for all subjects.

\section{Procedures}

In Test match 1 , team $A^{\prime}$ met team B (1 boxer in each weight category from 48 to $81 \mathrm{~kg}$ and 3 boxers at $91 \mathrm{~kg}$, for a total of 


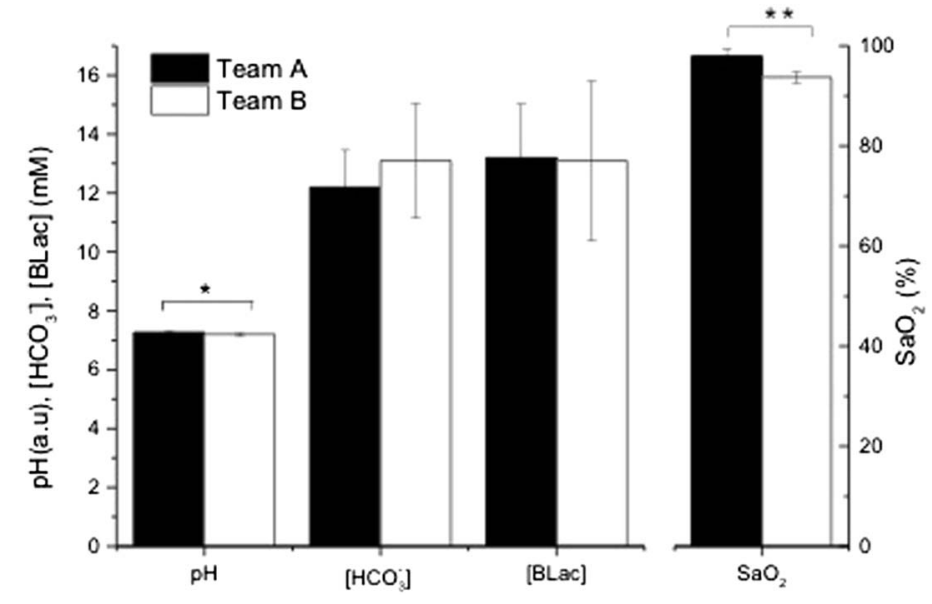

Figure 1. Blood metabolic responses after Test match 2 (team $\mathrm{A}$ and team $\mathrm{C}$ ). ${ }^{*} p \leq 0.05 ;{ }^{* *} p<0.001$. Subjects of all weight categories of teams $\mathrm{A}$ and $\mathrm{B}, n=20$.

tion $\left(\mathrm{SaO}_{2}\right)$, partial pressure for $\mathrm{CO}_{2} \quad\left(\mathrm{PCO}_{2}\right)$, and bicarbonate concentration $\left(\left[\mathrm{HCO}_{3}{ }^{-}\right]\right)$with an i-STAT dry chemistry analyzer (Abbott, Les Ulis, France). To test the effect of weight category on blood variables with a higher strength, the results of 2 of the next weight categories were averaged (48-51, 54-57, 60-64, 69-75, and 81-91), $N=$ 6 in each subgroup, except $N=$ $5(48-51 \mathrm{~kg})$.

\section{Number of Punches}

In the last round between team $\mathrm{A}^{\prime}$ and team $\mathrm{C}$, the number of punches given by each boxer was recorded by 2 experienced boxing coaches. To account only for the physical exertion, this score was made irrespec-

13 boxers), with data being collected from team A only due to the fact that team B did not wish to participate in the evaluations.

During Test match 2, team A met team C (10 boxers in each team and each weight category), and blood variables and given punches were collected for both teams. Five of 10 boxers were selected in team A and A'.

\section{Blood Variables Collection}

Three minutes after the end of the last round, arterialized capillary blood samples $(85 \mu \mathrm{L})$ were taken from hyperemized earlobes to measure blood $\mathrm{pH}$, [BLac], arterial oxygen satura-

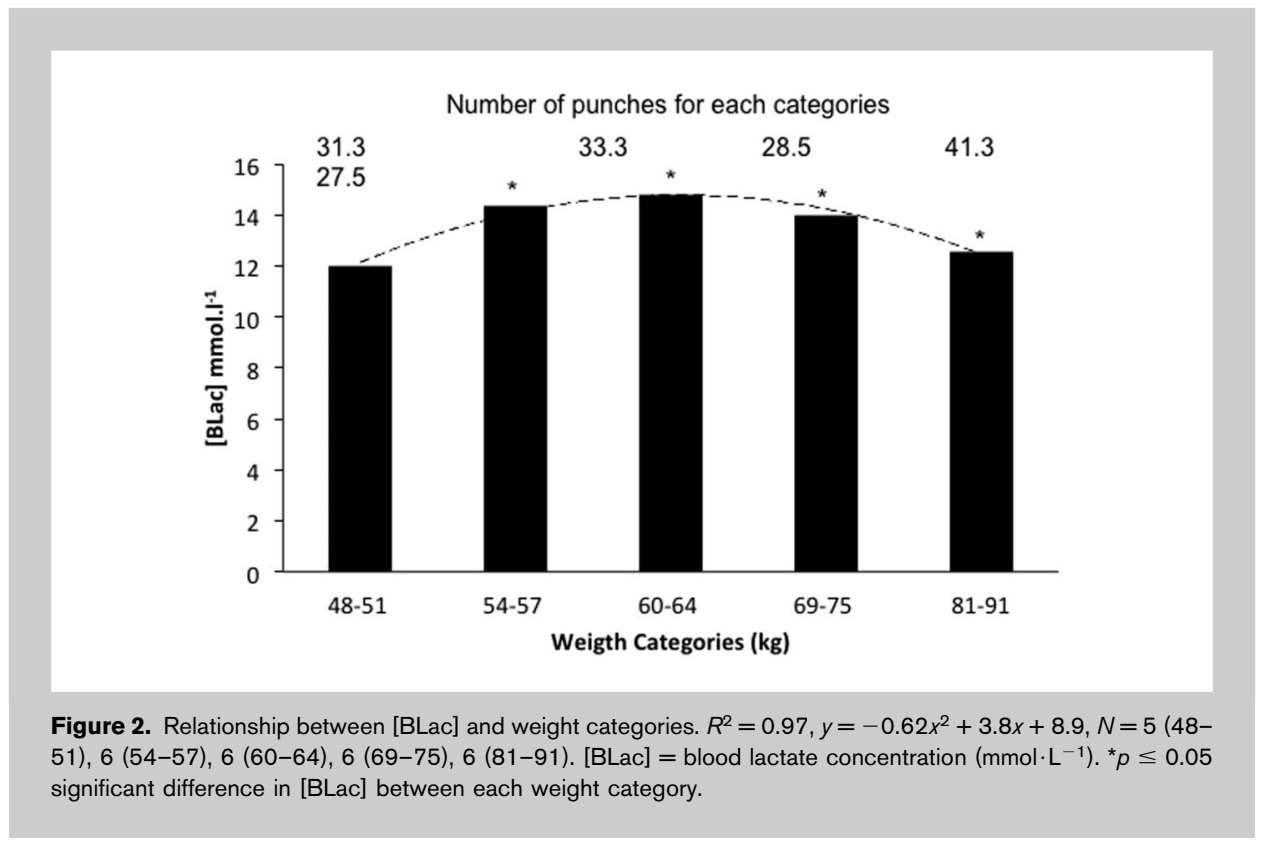

tive of whether the punch obtained a point from the judge. The retained final value corresponded to the average of the scores obtained by the 2 coaches.

\section{Statistical Analyses}

Data are presented as mean $\pm S D$. The level of significance was set at $p \leq 0.05$. To compare the postboxing metabolic responses of team $\mathrm{A}^{\prime}$ and $\mathrm{C}$, the Student $t$-test for unpaired data was applied. The difference in blood lactate concentration between each weight category was analyzed by a 1-way analysis of variance. When a significant $\mathrm{F}$ ratio $(p \leq 0.05)$ was obtained, a Student-Newman-Keuls test was used to locate significant mean differences. The relationship between [Blac] and the number of punches (team $\mathrm{A}^{\prime}+$ team C) was analyzed by a Pearson's correlation coefficient (version 5.0; Statview software, Berkeley, CA, USA). To answer the question of overall metabolic responses after a boxing match (Table 1) and the question of the influence of the weight class on lactate (Figure 2), 5 subjects were included twice (team $\mathrm{A}$ and $\mathrm{A}^{\prime}$ ). We consider also that boxer activity is inherently associated with the direct opponent and can vary greatly from match to match (19). Indeed, Varley and Aughey (19) suggested that the activity of a soccer player is influenced by the tactics of their team, the 
opposition team, and most importantly their direct opponent. Thus, the activity profile of a given individual will vary greatly from match to match (for boxing and soccer). As such, it is with this reasoning that we favor the approach of considering each boxer of teams $\mathrm{A}$ and $\mathrm{A}^{\prime}$ as an independent case, as did Varley and Aughey (2013).

\section{Results}

\section{Blood Data}

The blood metabolic data (team $\mathrm{A}$ in Test match 1 and team $A^{\prime}+$ team $C$ in Test match 2) are presented in Table 1. During Test match 2 (team $\mathrm{A}^{\prime}$ against team $\mathrm{C}$ ), a significant difference was observed for $\mathrm{pH}, \mathrm{SaO}_{2}, \mathrm{PCO}_{2}$, with values for team $\mathrm{A}^{\prime}$ and $\mathrm{C}$, respectively: $\mathrm{pH}(7.26 \pm 0.05$ and $7.20 \pm$ $0.06, p \leq 0.05), \mathrm{SaO}_{2}$ values $(97.9 \pm 1.6$ and $93.7 \pm 1.1$, $p<0.01)$ and $\mathrm{PCO}_{2}(27.1 \pm 2.8$ and $33.7 \pm 3.3, p<0.01)$ (Figure 1). No significant difference was noted between team $\mathrm{A}^{\prime}$ and $\mathrm{C}$ for [BLac].

When using a regression to reveal the evolution of the [BLac] data with weight categories (Figure 2), an inverted U (second degree polynomial) was the best fit $\left(y=-0.62 x^{2}+\right.$ $\left.3.8 x+8.9, R^{2}=0.97\right)$ with the intermediate category $(60-64$ $\mathrm{kg})$ being characterized by the highest [BLac] $(14.8 \pm 2.9)$ and the extreme categories (48-51 kg) and Super Heavy Weight (81-91 kg) being differentiated by the smallest values $(\sim 12$ $\left.\mathrm{mmol} \cdot \mathrm{L}^{-1}\right)$. There were significant differences in blood lactate concentration between each weight category $(p \leq 0.05)$.

The number of punches recorded in the last round of the Test match between team $\mathrm{A}^{\prime}$ and team $\mathrm{C}$ was $32.3 \pm 10.6$. The correlation measured between these values and [BLac] was $0.42(p=0.06)$. No effect from the weight category was detected on the number of punches $(p>0.05)$.

\section{Discussion}

The data recorded from elite amateur boxers over three 3-minute rounds in an Olympic format highlight alteration of acid-base balance during an elite boxing activity, with the lowest $\mathrm{pH}$ and $\left[\mathrm{HCO}_{3}{ }^{-}\right]$being reflected in the best worldclass boxers. These data also suggest that boxing in the intermediate category (57 and $64 \mathrm{~kg}$ ) induced the highest [lactate] and $\left[\mathrm{H}^{+}\right]$(Table 1$)$.

Given the limitation from coaches that we take only 1 single blood sample after an complete boxing bout, we chose to take the sample corresponding to the boxer's recovery duration (3 minutes), where postbout [BLac] has been shown to peak $\left(11.8,10.8\right.$, and $9.9 \mathrm{mmol} \cdot \mathrm{L}^{-1}$ at 3,5 , and 7 minutes, respectively) (8). Compared with previous data collected 20 years ago in elite boxers (18) for similar boxing bouts (three 3-minute rounds), these data demonstrated a large increase in postexercise lactate concentration $\left(8.2 \pm 2.9\right.$ and $\left.13.6 \pm 2.4 \mathrm{mmol} \cdot \mathrm{L}^{-1}\right)$. This increase could be due to the use of different lactate analyzers, a consequence of modified rules, and general sport professionalization over the past few decades or to the present more official context of the competition. Indeed, the opposition between teams $\mathrm{A}^{\prime}$ and $\mathrm{C}$ was very balanced and the boxers needed to maintain intensity until the end to win a match. Compared with the most recent study done with novice boxers (8), postmatch [BLac] was consecutive to 15-20 total punches recorded in the last round, whereas in this study, the number of punches was $>30$ and that could partly explain the difference in lactate concentration. Compared with other combat sports: Karate kata: $8 \mathrm{mmol} \cdot \mathrm{L}^{-1}(5)$, taekwondo: 3 (6) and 11 $\mathrm{mmol} \cdot \mathrm{L}^{-1}(2)$, judo: $12 \mathrm{mmol} \cdot \mathrm{L}^{-1}(9)$, boxing seems to require the greatest anaerobic contribution. In amateur boxing, Ghosh et al. (13) observed that anaerobic solicitation remained the same in all weight categories. In comparison, in international taekwondo competition, the activity profile was modulated by competitors' weight category (2).

Ghosh et al. (13) previously observed that anaerobic contribution remained the same in all weight categories in boxing, whereas the activity profile has been demonstrated to be modulated by a competitor's weight category in taekwondo (3), which is unlike this study where the highest values were recorded in the intermediate categories. In taekwondo, heavyweights are supposed to be subjected to greater fighting demands such as concentric and isometric actions of the upper- and lower-body musculature, and therefore to additional energy requirements. If we consider that [BLac] depends on both muscle mass involved and the level of glycolysis activation induced by the fighting demand, this result could indicate that the intermediate categories represent the highest combination of these 2 factors in boxing. An ineluctable limitation of this study performed with worldclass subjects is the number of data in each category. This methodological point makes a peremptory conclusion difficult. Nevertheless, the question of conditioning sessions specialized to the requirements of specific weight categories, as suggested in taekwondo, could be of interest in a boxing context.

To the best of our knowledge, this was the first time that the blood acid-base balance of boxing bouts was measured and collected. The $\mathrm{pH},\left[\mathrm{HCO}_{3}{ }^{-}\right]$, and $\mathrm{SaO}_{2}$ values were around $7.20,13 \mathrm{mmol} \cdot \mathrm{L}^{-1}$ and $95 \%$ with $7 / 20 \mathrm{pH}$ values $<7.20$. Because of the lack of available data recorded during competitive combats bouts, these values cannot be easily compared. These postexercise $\mathrm{pH}$ and $\left[\mathrm{HCO}_{3}{ }^{-}\right]$values reveal that world-class boxers must be able to tolerate a moderate, but substantial level of acidosis to produce high levels of boxing activity until the third round. Interestingly, the 3 boxers who presented the highest [BLac] and acidosis $\left(19 \mathrm{mmol} \cdot \mathrm{L}^{-1}\right.$ and $\left.<7.20\right)$ were the 3 best world-class boxers in their category and had already won a world title, which suggests the high anaerobic potential in these boxers. Furthermore, these 3 boxers threw more than 40 punches during the last round. Therefore, one can hypothesize that the best world boxers are able to achieve a high physical intensity during the 3 rounds and support a high level of acidosis.

These results also illustrate that there was no direct relationship between [BLac] and blood $\mathrm{pH}$ (1). If we 
compare team $\mathrm{A}$ and $\mathrm{A}^{\prime}$ data, one can note that a similar [BLac] did not induce similar $\mathrm{pH}$ values. In the same way, although the $[\mathrm{BLac}]$ were similar between team $\mathrm{A}^{\prime}$ and team $\mathrm{C}$ in the second Test match, the difference in $\mathrm{pH}$ values were significantly different, potentially indicating a better buffering capacity for team $\mathrm{A}^{\prime}$ compared with team $\mathrm{C}$ in the second Test match. One can then hypothesize that team A had improved its physical conditioning between Test match 1 and that the global buffering capacity of team $\mathrm{A}^{\prime}$ was more effective compared with team $\mathrm{C}$ during Test match 2. A greater buffering capacity has been shown to improve high-intensity exercise performance by allowing anaerobic glycolysis to continue during maximal exercise, resulting in a larger lactate production without a concomitant increase in $\mathrm{H}^{+}$accumulation (11)/or to a lower $\mathrm{H}^{+}$accumulation for a similar lactate production. The significance of a buffer capacity for boxing was demonstrated by the effectiveness of a loading dose of sodium bicarbonate to improve punching efficacy (16).

In the same way, when the values collected for team $\mathrm{A}$ and team $\mathrm{C}$ were compared, $\mathrm{pH}$ and $\mathrm{SaO}_{2}$ were statistically lower and $\mathrm{PCO}_{2}$ greater in team $\mathrm{C}$ compared with team $\mathrm{A}$. These lower $\mathrm{SaO}_{2}$ and $\mathrm{pH}$ values for similar [BLac] in team $\mathrm{C}$ compared with team $\mathrm{A}$ are questionable and could also be related to the quality of the mouthguards. Indeed, it has been previously demonstrated that noncustom mouthguards may reduce ventilation and oxygen uptake at maximal efforts by ice hockey players (10) that could be mediated by a reduced $\mathrm{Hb}$ saturation due to impaired ventilation. In this study, the significantly greater $\mathrm{PCO}_{2}$ values measured in team $\mathrm{C}$ compared with team $\mathrm{A}$ could also reflect impaired ventilation. This hypothesis needs to be tested to possibly focus on this point in boxing conditioning.

\section{Practical Applications}

Based on the [BLa] measured after the third round, this study highlighted the substantial alteration of the acid-base balance in international boxing competition. Postexercise $\mathrm{pH}$ and $\left[\mathrm{HCO}_{3}{ }^{-}\right]$revealed that world-class boxers must be able to tolerate a moderate, but substantial level of acidosis to produce high levels of boxing activity until the third round. It is of note that the 3 boxers who presented the greatest [BLac] and acidosis in comparison with others (19 $\mathrm{mmol} \cdot \mathrm{L}^{-1}$ ) and $<7.20$, were previous world champions, suggesting that the best world-class boxers are able to achieve a high physical intensity during the 3 rounds and support a high level of acidosis. Therefore, general or specific boxing training sessions aimed at improving buffering capacity could help boxers to score points in the last half of the rounds. Whether this lactate production would be more evident in the intermediate categories needs to be tested with a larger sample of elite boxers.

\section{ACKNowledgments}

The experiment described in this article complies with the current laws of the country in which they were performed. The authors are indebted to the subjects of this study and further appreciate the support of the French national boxing staff.

\section{REFERENCES}

1. Boning, D, Klarholz, C, Himmelsbach, B, Hutler, M, and Maassen, N. Extracellular bicarbonate and non-bicarbonate buffering against lactic acid during and after exercise. Eur J Appl Physiol 100: 457-467, 2007.

2. Bridge, CA, Jones, MA, and Drust, B. Physiological responses and perceived exertion during international Taekwondo competition. Int J Sports Physiol Perform 4: 485-493, 2009.

3. Bridge, CA, Jones, MA, and Drust, B. The activity profile in international Taekwondo competition is modulated by weight category. Int J Sports Physiol Perform 6: 344-357, 2011.

4. Buchfuhrer, MJ, Hansen, JE, Robinson, TE, Sue, DY, Wasserman, K, and Whipp, BJ. Optimizing the exercise protocol for cardiopulmonary assessment. J Applied Physiol Respir Environ Exerc Physiol 55: 1558-1564, 1983.

5. Bussweiler, J and Hartmann, U. Energetics of basic karate kata. Eur J Appl Physiol 12: 3991-3996, 2012.

6. Butios, S and Tasika, N. Changes in heart rate and blood lactate concentration as intensity parameters during simulated Taekwondo competition. J Sports Med Phys Fitness 47: 179-185, 2007.

7. Dal Monte, A and Menchinelli, C. Aspetti fisiologici del pugilato. Med Sport 39: 103-111, 1986.

8. Davis, P, Wittekind, A, and Beneke, R. Amateur boxing: Activity profile of winners and losers. Int J Sports Physiol Perform 1:84-91, 2013

9. Degoutte, F, Jouanel, P, and Filaire, E. Energy demands during a judo match and recovery. Br J Sports Med 37: 245-249, 2003.

10. Delaney, JS and Montgomery, DL. Effect of noncustom bimolar mouthguards on peak ventilation in ice hockey players. Clin J Sport Med 15: 154-157, 2005.

11. Edge, J, Bishop, D, and Goodman, C. The effects of training intensity on muscle buffer capacity in females. Eur J Appl Physiol 96: 97-105, 2006.

12. Friedmann, B, Jost, J, Rating, T, Weller, E, Werle, E, Eckardt, KU, Bartsch, P, and Mairbaurl, H. Effects of iron supplementation on total body hemoglobin during endurance training at moderate altitude. Int J Sports Med 20: 78-85, 1999.

13. Ghosh, AK, Goswami, A, and Ahuja, A. Heart rate and blood lactate response in amateur competitive boxing. Indian J Med Res 102: 179183, 1995.

14. Guidetti, L, Musulin, A, and Baldari, C. Physiological factors in middleweight boxing performance. J Sports Med Phys Fitness 42: 309-314, 2002.

15. Noakes, TD. Fluid replacement during exercise. Exerc Sport Sci Rev 21: 297-330, 1993.

16. Siegler, JC and Hirscher, K. Sodium bicarbonate ingestion and boxing performance. J Strength Cond Res 24: 103-108, 2010.

17. Smith, MS. Physiological profile of senior and junior England international amateur boxers. J Sports Sci Med 5: 74-89, 2006.

18. Vallier, JM, Brissswalter, J, and Hanon, C. Evaluation du métabolisme énergétique de la boxe anglaise de haut niveau de performance. Sci Sport 10: 159-162, 1995.

19. Varley, MC and Aughey, RJ. Acceleration profiles in elite Australian soccer. Int J Sports Med 34: 34-39, 2013. 